\title{
Internalism and Entitlement to Rules and Methods*
}

\author{
Joshua Schechter \\ Brown University
}

\begin{abstract}
In our thought, we employ rules of inference and belief-forming methods more generally. For instance, we (plausibly) employ deductive rules such as Modus Ponens, ampliative rules such as Inference to the Best Explanation, and perceptual methods that tell us to believe what perceptually appears to be the case. What explains our entitlement to employ these rules and methods? This chapter considers the motivations for broadly internalist answers to this question. It considers three such motivations - one based on simple cases, one based on a general conception of epistemic responsibility, and one based on skeptical scenarios. The chapter argues that none of these motivations is successful. The first two motivations lead to forms of internalismExtreme Method Internalism and Defense Internalism - that are too strong to be tenable. The third motivation motivates Mental Internalism (Mentalism), which does not fit with plausible accounts of entitlement.
\end{abstract}

\section{Introduction}

Here are two of the most important questions within epistemology:

(i) What explains the fact that we are by-and-large reliable in believing truths and disbelieving falsehoods?

(ii) What explains the fact that we are by-and-large justified in believing and disbelieving what we do?

These two questions have somewhat different flavors. We know - more or less - what it is to be reliable. To answer the first question, what is needed is an explanation of why it is that our beliefs have this status. ${ }^{1}$ In contrast, there is no uncontentious account of the nature of justification. To answer the second question, we must develop an account of what it is to possess this epistemic status.

\footnotetext{
* This is the penultimate draft of a paper for Nikolaj Jang Pedersen and Peter Graham (eds.), Epistemic Entitlement, Oxford: Oxford University Press.

${ }^{1}$ This question is perhaps most pressing for a priori domains such as logic, pure mathematics, and (fundamental parts of) morality.
} 
In answering these questions, progress can be made by focusing not on beliefs, but on reasoning (and on our transitions in thought more generally). ${ }^{2}$ As has been argued by Williamson and by Hill, it is plausible that our modal beliefs are reliable because we are reliable in our subjunctive reasoning. ${ }^{3}$ As I have argued elsewhere, our beliefs about logic are reliable because we are reliable in our deductive reasoning. ${ }^{4}$ Similarly, our basic perceptual beliefs are reliable because the perceptual mechanisms that generate them are reliable. And so on for many other domains.

Not only is this change of focus helpful for making progress toward answering the first question, it is helpful for making progress toward answering the second. It is plausible that our modal beliefs are justified (in part) because we are justified in reasoning subjunctively as we do. We are justified in our logical beliefs (in part) because we are justified in reasoning deductively as we do. We are justified in our basic perceptual beliefs because we are justified in moving from experiential states to perceptual beliefs as we do. And, again, the analogous claims apply for many other domains. According to this line of thought, the epistemic credentials of our reasoning (and our transitions in thought more generally) are - at least in many cases - prior to the epistemic credentials of our beliefs.

The nature of reasoning is a vexed topic. But on a very natural picture, reasoning is a rule-governed activity. Our reasoning is governed by rules of inference. More generally, our transitions in thought are governed by belief-forming methods. There are three principal grounds for this claim. First, appealing to rules and methods is the most promising strategy for explaining the difference between genuine reasoning and mere

\footnotetext{
${ }^{2}$ In this paper, I use 'reasoning' to refer to theoretical rather than practical reasoning.

${ }^{3}$ See Hill (2006) and Williamson (2007), chapter 5.

${ }^{4}$ See Schechter (2010).
} 
change in belief. Second, we are familiar with two different sorts of mistakes thinkers may make in their reasoning - errors of competence and errors of performance. Appealing to rules and methods can help to explicate this distinction: Thinkers may employ the wrong rules, or they may misapply the rules that they employ. ${ }^{5}$ Finally, there are good candidates for the rules and methods that we in fact employ - deductive rules such as Modus Ponens, ampliative rules such as Inference to the Best Explanation, as well as perceptual methods that tell us to believe what perceptually appears to be the case.

A terminological clarification may be helpful here. In what follows, I'll use 'rules of inference' as a subset of 'belief-forming methods'. Rules of inference are those beliefforming methods that are relevant to inferential reasoning. As a rough approximation, we can think of them as belief-forming methods where both the inputs and outputs are beliefs or belief-like states. ${ }^{6}$

It shouldn't be pretended that there are no obscurities in a rule-governed picture of reasoning. ${ }^{7}$ On pain of infinite regress, it must be the case that we can follow rules of inference without explicitly representing them in our thought. It is difficult to understand how this could be possible. How is it that thinkers can count as genuinely following rules - and not merely conforming to them - without explicitly representing them? The answer to this question is not at all clear. Moreover, it is natural to think that certain rules are rules of permission. Other rules are rules of obligation. It is not clear how this distinction can be made out for rules that are followed but not explicitly represented. These are

\footnotetext{
${ }^{5}$ See Boghossian (2005).

${ }^{6}$ This may need to be broadened to include reasoning with suppositions, as occurs in reductio arguments and in Reasoning by Cases.

${ }^{7}$ See Kripke (1982) and Boghossian $(1989 ; 2008)$ for discussion.
} 
genuine difficulties for a rule-based conception of reasoning. But I am not aware of any alternative picture that can do the same work in explaining the nature of reasoning.

There is an important distinction that ought to be raised here, one that will be important in what follows. This is the distinction between basic and non-basic beliefforming methods. Certain belief-forming methods are basic (for us). They are basic in an intuitive sense - they are the most fundamental methods we employ in reasoning. In other words, these methods are the ones that are employed but not in virtue of employing any other methods. Plausible examples of such methods include Modus Ponens, Inference to the Best Explanation, as well as the fundamental methods governing our perceptual, modal, and moral thought. ${ }^{8}$

Just as a thinker's beliefs can be justified or unjustified, so too can her employment of belief-forming methods. These two notions are related in roughly the following way: A thinker is justified in employing a rule just in case the thinker is pro tanto justified in believing the output of the rule when it is applied to justified input beliefs, and is justified in believing the output because the belief was so formed. More generally, a thinker is justified in employing a belief-forming method just in case the thinker is pro tanto justified in believing the output of the method when it is applied to justified inputs (where the question of the justification of the inputs arises), and is justified in believing the output because the belief was so formed. ${ }^{9}$

\footnotetext{
${ }^{8}$ See Wedgwood (2002) for a discussion of basic methods. There are other basic/non-basic distinctions. For instance, a method may be basic in the sense that having justification to employ it does not require being justified in believing that it is reliable. I believe that there are basic rules in this second sense, too. That is, in fact, part of the point of this paper. But I'll officially use 'basic' in a non-normative sense.

${ }^{9}$ These theses must be further generalized to handle cases where the output is not a belief, but a disbelief or a different kind of mental state.
} 
Notice that this claim is not merely a biconditional. It also has an explanatory component. In particular, beliefs are justified because they were formed by applying justified belief-forming methods to justified inputs (where the question of justification arises). This explanatory claim is intuitively very plausible. To give a simple example, a thinker may be justified in believing a mathematical theorem because she inferred it from more basic mathematical principles she was justified in believing using deductive rules she was justified in employing. Similarly, a thinker may be justified in believing that there is an apple on the table because she had a certain visual experience and she transitioned from the experience to the belief using a belief-forming method she was justified in employing.

This general picture of the relationship between belief, reasoning, and rulefollowing raises the following important questions about justification:

In virtue of what are we epistemically justified in employing certain belief-forming methods and not others? In particular, in virtue of what are we justified in employing many of the belief-forming methods that we employ?

I take these questions to be central questions about epistemic justification. They are the primary questions in this area of epistemology.

In this paper, I'm not going to answer these questions directly. Rather, I'm going to discuss various desiderata on an acceptable answer.

There are several desiderata on a satisfying account that can be agreed upon by (nearly) everyone. Here are six: (i) The account of justification should be extensionally adequate. In particular, its extension should seem reasonable - it should more-or-less fit with our pre-theoretic judgments. Where it doesn't, there must be some story about how conflicting judgments are to be explained away. (ii) The account should show why we are 
justified in employing certain methods. That is, it should not merely provide necessary and sufficient conditions. It should also present an explanation of why it is that we are justified. (iii) The account should provide the fundamental explanation of our justification. It should identify the fundamental normative principles governing this normative status. Of course, one may be interested in discovering a correct account of justification, whether or not it is fundamental. But it would be most satisfying to provide the fundamental account. (iv) The account of justification should be unified, non-ad hoc, and possess the usual theoretical virtues. (v) On the account, justification should be appropriately connected with truth. There should be a sense in which we are more likely to arrive at the truth using justified methods than non-justified methods. ${ }^{10}$ (vi) Finally, on the account, justification should be appropriately normatively significant. In other words, the account should show justified methods in a positive rational light. To borrow a term used by Feigl, the account should vindicate justified methods. ${ }^{11}$

The central issue of this paper concerns another class of putative constraints. The issue is whether there are any internalist constraints on an adequate account of the justification of rules inference and belief-forming methods.

What do I mean by 'internalist' in this context? Here are several candidate internalist constraints:

(i) A thinker is justified in employing a belief-forming method only if the thinker has a (doxastically) justified belief that the method is reliable (or that it has some other positive epistemic status). ${ }^{12}$

(ii) What makes it the case that a thinker is justified in employing a beliefforming method is solely a matter of what is internal to the thinker's mind.

\footnotetext{
${ }^{10}$ Similarly, justification should be appropriately tied to evidence.

${ }^{11}$ See Feigl (1952).

${ }^{12}$ An alternative constraint would require that the thinker has proposition justification to believe that the method is reliable (or otherwise has some positive epistemic status). As I argue below, such a constraint lacks the intuitive motivation of the constraint requiring a doxastically justified belief.
} 
(iii) Whether a thinker is justified in employing a belief-forming method supervenes on the thinker's internal mental states.

(iv) Whether a thinker is justified in employing a belief-forming method supervenes on what's accessible to the thinker by reflection alone.

In what follows, I'm going to argue against such constraints. There are no internalist constraints on an adequate account of our justification to employ certain rules of inference and belief-forming methods. 'Rule internalism' and 'method internalism' are false.

\section{Justification, Entitlement, and Epistemic Responsibility}

Before I turn to rule and method internalism, it is important to get more of a fix on the target notion of justification. One of the lessons of contemporary epistemology is that there may be several different properties that are referred to by 'justification.' There are certainly different concepts of justification. For instance, some philosophers characterize justification as that which when added to true belief yields knowledge (modulo some condition to handle Gettier cases). ${ }^{13}$ This is not the notion that I have in mind.

The concept of justification that I will work with here may well be conceptually primitive. If you don't already possess it, it may be difficult or impossible for me to communicate it to you. But I hope that you share the notion with me.

It is common to introduce this notion by talking about what a thinker epistemically ought to believe. By analogy to morality, a distinction is then made between objective and subjective oughts. It is the latter that is claimed to be of interest. ${ }^{14}$

\footnotetext{
${ }^{13}$ This is what Plantinga (1993) calls 'warrant'.

${ }^{14}$ This is because it is tempting to think that thinkers objectively ought to believe all and only the truths. (Interestingly, the analogous claim for rules doesn't hold - there is no sense of 'ought' on which thinkers objectively ought to reason in every truth-preserving way.) On an alternative view, familiar from Williamson (2000), thinkers objectively ought to have all and only those beliefs that constitute knowledge.
} 
A thinker is justified in believing a proposition just in case she subjectively ought to believe it. A thinker is justified in employing a method just in case she subjectively ought to employ it. That, it is claimed, is what epistemic justification is.

I find this way of introducing the notion helpful, but also somewhat problematic. It is controversial whether there really is a principled distinction between subjective and objective oughts. More importantly, justification is more of a notion of permission than a notion of obligation. We are permitted to believe what we are justified in believing. At least in some cases, we are not also obligated to believe it.

I find it more helpful to say that a thinker is justified in believing a proposition just in case the thinker is epistemically responsible in holding the belief. (For some reason, it is sometimes more helpful to say that the thinker is 'not epistemically irresponsible' in holding the belief.) A thinker is justified in employing a belief-forming method just in case the thinker is epistemically responsible in employing the method. ${ }^{15}$

To state the obvious: Justification is a positive normative status. It is also an epistemic status, not a moral or pragmatic status. To state the less obvious: Being justified in holding a belief is not the same as being epistemically blameless in holding it. This is for two reasons. First, we do not have a systematic practice of epistemically blaming people for their beliefs or reasoning prowess. ${ }^{16}$ We don't typically have any of the Strawsonian reactive attitudes - blame, guilt, and resentment - to people who have a

\footnotetext{
${ }^{15}$ I should point out that adopting a responsibilist conception of justification makes my task of arguing against internalism harder. Many externalists give up on anything like a responsibilist conception. That is part of what's behind the familiar charge that endorsing reliabilism about justification is a matter of changing the subject.

${ }^{16}$ As an anonymous referee reminds me, we sometimes morally blame people for their beliefs - e.g., racist and sexist beliefs. And the appropriateness of such blame can depend on whether the thinker reasoned correctly. But the kind of blame in question is moral blame.
} 
belief that is not properly based on the evidence or who otherwise reason poorly. ${ }^{17}$ There is a broader sense of 'blame' according to which we sometimes seem to epistemically blame people for their beliefs and reasoning. But it doesn't seem that we do so in any very systematic way. Second, it can be natural to describe thinkers as blameless but unjustified. This can happen when they have a (good) excuse for their belief. ${ }^{18}$ For example, if someone reasoned incorrectly on some trivial matter because they were distracted by something important, a natural description of the situation is that they are blameless but unjustified in their belief. ${ }^{19}$

There is another clarification worth making: To responsibly believe a proposition or employ a method, a thinker need not have carried out the relevant inquiry in a fully responsible way. A person can be responsible in believing a proposition given her evidence despite the fact that she has been lazy or careless in collecting evidence and inquiring into the issue. The same holds true in the practical domain: A person can behave responsibly in solving a problem, even though the person is otherwise irresponsible, the problem was of her own making, etc.

This, then, is the target notion of justification I'll be working with. Of course, there are several questions and obscurities that remain. But I take it that the notion is at least tolerably clear for my purposes here.

Finally, let me say a bit about entitlement. The term 'entitlement' is used in several different senses in the literature. ${ }^{20}$ On one important usage, a thinker is entitled to

\footnotetext{
${ }^{17}$ See Strawson (1962).

${ }^{18}$ See Austin (1956) for the classic discussion of excuses. See Littlejohn (forthcoming) and Williamson (forthcoming) for a discussion of excuses as they are relevant to epistemology.

${ }^{19}$ The same holds true for action. We do sometimes want to say of someone that they have acted irresponsibly - for instance, in failing to turn off the oven - without being blameworthy - for instance, because they were distracted by something important.

${ }^{20}$ See Burge (1993), Dretske (2000), and Wright (2004) for classic discussions of entitlement.
} 
believe a proposition just in case the belief is warranted but is not so warranted on the basis of being supported by evidence. In this paper, I'll use 'entitlement' in a related way, but in application to rules of inference and belief-forming methods. On my usage here, a thinker is entitled to employ a belief-forming method just in case the thinker is justified in employing the method as basic but is not so justified on the basis of having a doxastically justified belief (or has propositional justification to believe) that the method is reliable, justified, or has some other positive epistemic status. ${ }^{21}$ This characterization is not strictly analogous to the characterization of entitlement for beliefs - for instance, it does not directly appeal to what is (or is not) supported by evidence. But the central idea is similar.

Most of the discussion to follow will concern justification rather than entitlement. But the nature of entitlement to rules and methods will loom large toward the end of this paper.

\section{The Argument from Examples}

Should we accept an internalist constraint on providing an account of the justified employment of belief-forming methods? I claim that the answer is no. To give a bit of the game away, there will be several general morals of this paper. First, the intuitive motivations for internalist constraints are heterogeneous. (This is a familiar claim from the literature.) Second, these motivations directly motivate distinct internalist constraints. (This is also familiar from the literature.) What may be less familiar is a third moral: The

\footnotetext{
${ }^{21}$ In the literature, the terms 'entitlement' and 'justification' are typically employed so that they stand for incompatible epistemic statuses. In this paper, I use the term 'justification' broadly. I take entitlement to be a species of justification. I find this terminology more congenial. It also better fits with the terminology in Enoch and Schechter (2008).
} 
main motivations for internalist constraints directly motivate extremely strong internalist constraints. In particular, they do not motivate restricting the internalist theses to rules of inference rather than to belief-forming methods more generally. They also do not motivate internalist constraints that appeal to considerations of access.

In what follows, I'm going to focus on three motivations for internalist constraints. These are the ones that I find the most compelling. In the remainder of this section, I will discuss a motivation based on simple cases. In the next section, I will discuss a motivation based on a general conception of what it is to be a responsible thinker. In the section after that, I will discuss a motivation based on our reactions to skeptical scenarios. ${ }^{22}$

\subsection{Examples}

The first motivation for rule internalism is based on an examination of several simple examples. The most striking kind of case is that of our use of measuring instruments - for instance, our use of thermometers.

The following claim is very intuitive: A thinker is justified in relying on her favorite thermometer to determine the local temperature only if she has an independently

\footnotetext{
${ }^{22}$ There are other motivations for internalist constraints but they strike me as less powerful than the three I discuss in the main body of the text. Here are a few: (i) Justification is a matter of belief-guidance. Indeed, Goldman (1999) suggests that this is the main motivation for internalism. I do not have the space to discuss this motivation here, other than to say that I agree with much of what Goldman says in response to it: Either the constraint is way too strong or it is incapable of supporting internalism. (ii) We have a (rather inchoate) intuition that justification is purely a matter of what's 'going on' with the thinker. I take it that this intuition should not be taken fully seriously, since (for example) the fact that we are justified in employing the rule Modus Ponens seems to also depend in part on the logical fact that Modus Ponens is valid, which is not a fact about the thinker. (iii) Justification for employing a method can be defeated by a justified belief that the method isn't reliable. This, it might be argued, suggests that a justified belief that the method is reliable was somehow responsible for the justification. This suggestion is untenable for the case of deductive rules, for the reasons familiar from discussions of Carroll (1895). (iv) The unpalatable nature of Moore-like sentences - 'P, therefore Q but I don't believe that that rule is good' - suggests that we adopt an internalist constraint. I take it that Moore-like sentences are not very probative, since they can be used to support absurdly strong constraints on justification and knowledge.
} 
justified belief that the thermometer is reliable. The grounds justifying the belief need not be specific to the thermometer in question. For instance, it may suffice that the thinker justifiably believes that manufactured thermometers tend to be pretty reliable. But some independent justification of the reliability belief seems necessary. (The restriction to independent justifications is needed because it clearly would be no good if the thinker was convinced of the reliability of the thermometer by testing it against itself. This requirement is, in effect, a 'no bootstrapping' constraint.)

An analogous claim is intuitive for more complex devices. Suppose you own a complicated computational device that outputs a grammatical sentence of English whenever you hit a particular button. A thinker is not justified in believing the output of such a device unless she has an independently justified belief that the device tends to output truths.

Generalizing from these examples, the following principle is very attractive:

Measuring Instruments: A thinker is justified in relying on a measuring instrument only if the thinker has an independently justified belief that the instrument is reliable.

There is some intuitive pull in favor of the view that an analogous claim applies to cases of testimony. Take, for instance, a thinker's reliance on an oracle, say the oracle at Delphi. It is plausible that a thinker is justified in relying on the testimony of an oracle only if she has an independently justified belief that the oracle is reliable. Similarly, a member of a jury is justified in relying on the testimony of a witness at a trial only if she has an independently justified belief that the witness is reliable.

Generalizing from these cases, we arrive at the following principle: 
Testimony: A thinker is justified in relying on the testimony of a speaker only if the thinker has an independently justified belief that the speaker's testimony is reliable.

This principle is somewhat less convincing than the first. Indeed, it is highly contentious in the literature on testimony. But the principle is prima facie at least somewhat plausible.

Taking these examples seriously, there is a natural further generalization to make: A thinker is justified in relying on a belief-forming method in her thinking only if the thinker has an independently justified belief that the method is reliable.

Notice that this constraint requires that the thinker actually have a justified belief in the reliability of the method. That is the constraint that the examples directly support. If a thinker doesn't actually believe that a thermometer is reliable, for instance, she shouldn't make use of it.

It is easy to motivate further strengthening this generalization from a conditional to a biconditional. What more could be required to be justified in employing a method than to have a justified belief that the method is reliable? Having the justified belief that a particular thermometer is reliable would seem to suffice for being justified in relying on it.

The examples also motivate a claim about explanation: The thinker is justified in relying on the thermometer because she has a justified belief that it is reliable. It is in virtue of her justified belief that she is justified in employing the method.

It is worth pointing out that reliability may not be the only relevant status. If a thinker has a justified belief that she is justified in relying on her favorite thermometer - 
whether or not she has a justified belief that it is reliable - she may still be justified in relying upon it. So we can slightly liberalize our principles. ${ }^{23}$

Putting this all together, we arrive at the following general thesis:

Extreme Method Internalism: A thinker is justified in employing a beliefforming method just in case and by virtue of the fact that the thinker has an independently justified belief that the method is reliable (or is a method that she is justified in employing, or otherwise has a positive epistemic status).

For simplicity, let us call a belief that a method is reliable (or is a method that one is justified in employing or otherwise has a positive epistemic status) a 'backing belief' of the method. Extreme Method Internalism is the thesis that a thinker is justified in employing a method just in case and by virtue of the fact that she has a justified backing belief of the method. This is the thesis that is directly motivated by the examples. It is a very strong version of method internalism.

One might try to further support this thesis by appealing to BonJour's case of Norman, the reliable clairvoyant, or to Lehrer's case of Mr. Truetemp. ${ }^{24}$ In these cases, the relevant thinkers lack justified backing beliefs for their methods. They also apparently fail to be justified in employing them. These cases, then, might be thought to be something like negative controls for Extreme Method Internalism. However, the BonJour and Lehrer cases are very tricky to evaluate. Our intuitions about them fluctuate when we make apparently minor modifications to them. Consider the case of a reliable clairvoyant for whom clairvoyance has a rich quasi-perceptual phenomenology. It is less obvious that such a clairvoyant is not justified in relying upon his clairvoyance. Similarly, modify the case so that the clairvoyant doesn't have a visual faculty but only a faculty of

\footnotetext{
${ }^{23}$ I owe this observation to Paul Boghossian.

${ }^{24}$ See BonJour (1980) and Lehrer (2000).
} 
clairvoyance. Our intuitions - or, at least, my intuitions - get muddier, still. Evaluating these kinds of cases is very tricky. Ultimately, I suspect that such cases are not very probative.

Nevertheless, Extreme Method Internalism has an air of plausibility. It fits well with the simple cases we have considered and does not seem obviously false.

\subsection{Against Extreme Method Internalism}

Despite its plausibility, Extreme Method Internalism is subject to serious problems.

Consider the following two claims:

(i) A thinker is justified in employing a belief-forming method just in case and solely by virtue of the fact that the thinker has an independently justified backing belief of the method.

(ii) A thinker is justified in holding a belief just in case and solely by virtue of the fact that the belief was generated by the application of a belief-forming method that the thinker was justified in employing to justified inputs (where the question of the justification of the inputs arises).

The first claim is a restatement of Extreme Method Internalism. The second claim is independently very plausible. Indeed, it already appeared in the Introduction under a slightly different guise.

The trouble is that the two claims cannot both be true. The chief difficulty here is not the usual sort of infinite regress problem. The usual sort of problem would go like this: The two claims jointly entail that to be justified in employing a method, a thinker must have infinitely many justified beliefs. Given the finitude of our epistemic capacities, that is impossible. So at least one of the two claims is false. 
That may well be a problem, but I'm not going to focus on it here. This is because the line of thought turns on subtle issues concerning the nature of independent justifications.

Instead, the difficulty that I'd like to present is that the two claims listed above launch an explanatory regress. Indeed, there are really two problems concerning explanation here. The first is an infinite regress problem, just not an infinite regress of the usual sort. Formally put, the problem is that the explanatory grounding relation - the relation that holds between a fact and the facts that explain it - has no infinite chain. ${ }^{25}$ In other words, tracing this relation from an explanandum to its explanans, to the explanans of each of the explanans, and so on, must terminate. Since the two claims above entail that there is an infinite explanatory chain, at least one of the two claims must be false.

Notice that this problem does not turn on anything to do with independence. It does not turn on the finitude of our capacities. It also does not turn on my earlier claim that the simple examples directly motivate the requirement that the thinker actually holds a backing belief (and is not merely in a position to believe it). Rather, the problem turns on a very general feature of the explanatory grounding relation. ${ }^{26}$

Why believe that the grounding relation has no infinite chains? As far as I can tell, there is no fancy argument for this claim. However, the claim has been taken for granted by many. It is deeply intuitive that explanations have to bottom out somewhere. ${ }^{27}$

\footnotetext{
${ }^{25}$ See Fine $(2001 ; 2012)$, Rosen (2010), and Schaffer (2009) for discussion of the grounding relation.

${ }^{26}$ Notice that this problem still arises if 'solely' is replaced by 'partially' in the two above claims.

${ }^{27}$ In conversation, Jonathan Schaffer has suggested that relations lack infinite chains when they transmit an important status. For instance, since the relation between explanans and the explanandum they explain transmits the status of being explained, there must be minimal explanatory elements. This proposal has some plausibility - without minimal elements, it is difficult to see how the status of being explained can get off the ground. However, there are apparent counterexamples. For example, the relation between a cause and its effects also transmits an important status - that of being causally explained. This does not obviously entail that there are always first causes.
} 
The second explanatory problem resembles a circularity problem. The two claims listed above jointly yield an explanatory structure with the following shape: The justification of belief-forming methods is completely grounded in the justification of beliefs. The justification of beliefs is completely grounded in the justification of methods (and the justification of beliefs). This is not a possible explanatory structure.

To help explicate this problem, consider a clear case of an explanatory circularity. Consider a case in which the fact that $\mathrm{p}$ is supposed to totally explain the fact that $\mathrm{q}$, and the fact that $\mathrm{q}$ is supposed to totally explain the fact that $\mathrm{p}$. Such an explanatory structure is intuitively problematic. The explanatory grounding relation is plausibly transitive and irreflexive ${ }^{28}$ At the very least, its transitive closure is plausibly irreflexive. It cannot contain such loops.

What we have here is not quite that strong. There need not be any pair of facts such that each is supposed to completely explain the other. There is no obvious violation of transitivity or reflexivity. But what we do have is a case in which there are two natural classes of facts such that each member of the first class is completely explained by members of the second class, and each member of the second class is completely explained by members of the first class (along with members of the second). This is not a problem with the logical features of the grounding relation, per se. But it is intuitively problematic, as well. ${ }^{29}$

It may be worthwhile to ward off some immediate concerns about this second explanatory problem. One might think that the explanatory structure is relevantly like that of a recursive definition. Thus, it might be thought that this structure is unproblematic.

\footnotetext{
${ }^{28}$ But see Schaffer (2012) for argument that metaphysical grounding is not transitive and Jenkins (2011) for argument that metaphysical grounding may not be irreflexive.

${ }^{29}$ Notice that this problem also arises if 'solely' is replaced by 'partially' in the two claims above.
} 
But the explanatory structure that is entailed by the two above claims does not resemble a recursive definition. To have a genuine recursive definition, there must be basis clauses. On the explanatory structure entailed by the two claims, there is no basis.

One might instead think that the explanatory structure is relevantly similar to the structure of explanation posited by theorists who endorse reflective equilibrium or coherentist pictures of justification. Insofar as such pictures do not suffer from an explanatory regress problem, it might be thought that neither does Extreme Method Internalism.

This, however, is also a mistake. On coherentist pictures, the justification of a belief-forming method is not explained by the justification of beliefs and vice-versa. Rather, on a coherentist picture, what's directly justified is not an individual belief or method, but a package of beliefs and methods. What explain the justificatory status of a package are facts about the coherence of the package. On such a picture, there is no need to posit infinite explanatory chains or a quasi-circular structure to explanation. ${ }^{30}$

I conclude, therefore, that we cannot accept both of claims (i) and (ii) above.

If we have to chose between one of these claims, claim (ii) is the winner. It is extremely natural to accept that our beliefs are justified in virtue of being formed by the application of justified belief-forming methods to justified inputs. This is far more natural than accepting claim (i).

These problems, of course, do not show that claim (i) is false when shorn of its explanatory implications. That is, I have not said anything that entails that the biconditional underlying claim (i) is false. However, the explanatory problems do show that the motivation for the biconditional goes astray. Since this motivation fails, we are

${ }^{30}$ For a version of this point, see, for example, BonJour (1985). 
left with no good reason to accept an internalist constraint, at least not on the basis of the simple examples.

Why, then, do we feel the pull of Extreme Method Internalism? There is a natural diagnosis to offer: We overgeneralize from examples. Recall the distinction between basic and non-basic belief-forming methods. In our thinking about the justification of belief-forming methods, we need to carefully distinguish between these classes of methods. Extreme Method Internalism is plausible when restricted to non-basic methods. To be justified in employing one of those methods, we need to have a justified backing belief. For basic methods, no justified backing belief is required.

\section{The Argument from Responsibility}

\subsection{Epistemic Responsibility and Defending One's View}

The second motivation for rule internalism depends on a general conception of what it is to be a responsible believer. The central idea is that it is epistemically irresponsible to believe a proposition without having a sufficiently strong defense of the belief. This is an attractive thought about epistemic responsibility, at least upon first blush.

What is it to have a defense of a belief? Let me say a few things to fill in the intuitive picture.

One might make the following claim: It is irresponsible to believe a proposition without possessing an argument in favor of the truth of the proposition. This is much too strong as a construal of the idea that we should have defenses of our beliefs. A defense might be an argument in favor of the truth of the relevant proposition. But, alternatively, it might be an explanation of why it is epistemically acceptable to believe the 
proposition. ${ }^{31}$ A defense only needs to be something that supports - in either a justificatory or an explanatory way - the thinker's belief or the proposition that is believed. In short, a defense must somehow legitimate holding the belief.

For something to count as a defense, the relevant thinker must be able to recognize it as a defense. The motivating picture is that in believing a proposition, a thinker is putting something forward - she is staking a claim. To legitimately stake a claim, the thinker had better have a defense of it. But not only must she possess a defense of her claim, she had better be able to recognize the defense as such. If she isn't able to recognize the defense, she doesn't really have a defense at all.

Indeed, it is plausible that the thinker has to do more than be in a position to recognize her defense as a defense. She had better actually recognize it as a defense. A defense of a claim is no good if you don't in fact recognize it as such, whether or not you are able to do so. This requirement, however, is very strong. It quickly leads to a regress problem. In the interests of charity, then, I won't insist upon the point.

A defense need not be able to rationally convince a skeptic or neutral party. It need only be rationally convincing to the thinker in question. This is one of the lessons of contemporary epistemology - trying to convince a committed skeptic is a mug's game. But it is a necessary part of having a defense of a belief that the thinker in question be satisfied with the defense and that she be rationally satisfied with it.

For a defense to be rationally satisfying, it had better not be trivial or grossly circular. After all, one cannot defend - justify or explain - a belief by appealing to the

\footnotetext{
${ }^{31}$ There are other kinds of defenses, too. As an anonymous referee points out, certain kinds of explanations of how it is that I came to have a belief may also count as defenses.
} 
very belief in question. This motivates a (perhaps weak) independence requirement on defenses.

For a defense to be acceptable, it must itself be justified. In particular, the beliefs appealed to in the defense must be justified. The methods employed by the thinker in the defense must be ones that the thinker is justified in employing. I take it that this is straightforward: An unjustified defense is not a defense at all.

Finally, it should be acknowledged that the need for a defense (at most) applies to sufficiently cognitively sophisticated thinkers. It is sometimes suggested that some forms of internalism are false on the ground that they wouldn't enable children and non-human animals to count as justified - they are cognitively too demanding. While I have some sympathy for this general kind of complaint, this particular instance of it seems mistaken. We should think that with greater cognitive power comes greater responsibility. ${ }^{32}$ Children and animals need not have a defense to count as justified, since (roughly speaking) they couldn't come up with a defense if they tried. ${ }^{33}$ By contrast, we need a defense. This is a consequence of a plausible version of the principle that ought-impliescan.

Given these clarifications, we can now state the following constraint on justification:

Defense Internalism ${ }_{B}$ : A thinker is justified in believing a proposition only if the thinker has an independently justified defense of the belief.

\footnotetext{
${ }^{32}$ Apologies to Stan Lee.

${ }^{33}$ Alternatively, one might claim that children and animals do not count as justified - at least not in the same sense that we do.
} 
This is a principle concerning the justification of beliefs. By analogy, one might extend this line of thought to rules of inference and to belief-forming methods more generally. This yields the following principle:

Defense Internalism ${ }_{M}$ : A thinker is justified in employing a belief-forming method only if the thinker has an independently justified defense of the method.

Defense Internalism $\mathrm{M}_{\mathrm{M}}$ is in some ways weaker than Extreme Method Internalism. For instance, possessing a defense doesn't require a thinker to hold a backing belief - an explanation of how it could be acceptable to employ the method would suffice.

Nevertheless, Defense Internalism $m_{M}$ is also a very strong form of method internalism.

\subsection{Against Defense Internalism}

Despite the appeal of a defense-based conception of epistemic responsibility, Defense Internalism $\mathrm{M}_{\mathrm{M}}$ ought to be rejected.

One concern with Defense Internalism $\mathrm{M}_{\mathrm{M}}$ stems from the fact that Defense Internalism $\mathrm{B}_{\mathrm{B}}$ is motivated by the idea that believing a proposition is broadly analogous to making a claim or staking a position. However, employing a rule or a method is not a matter of explicitly staking a position. So the analogy does not obviously succeed. Even if Defense Internalism $\mathrm{B}_{\mathrm{B}}$ is correct, we need not accept Defense Internalism $\mathrm{M}_{\mathrm{M}}$.

This problem is not decisive. Employing a method is not a matter of explicitly staking a position. However, employing a method does entail that the thinker implicitly treats certain inputs as supporting certain outputs. So there is a case to be made that employing a method is bound up with the implicit staking of a claim. Why doesn't this need defense, too? Given this line of thought, I don't want to lean on the disanalogy too 
strongly. The main lesson here is just that the intuitions supporting the need for defenses are murkier for the case of rules and methods than they are for the case of beliefs.

A second problem is that a defense-based conception of responsibility does not merely motivate a conditional. As before, the line of thought motivates an explanatory connection. In particular, it motivates the following principle:

A thinker is justified in employing a belief-forming method only if and (in part) by virtue of the fact that the thinker has an independently justified defense of the method.

As before, this yields an explanatory regress. Essentially the same two explanatory problems emerge for this constraint as for Extreme Method Internalism. There is one small difference - in some cases, the thinker's justification for employing the method is not completely explained by the fact that the thinker has a defense of the method. More may be required for the thinker to be justified. But this is not a relevant difference. The two explanatory problems retain their bite.

I take it that these problems are decisive. They show that there is something wrong with a defense-based conception of epistemic responsibility. This problem undercuts the motivation for Defense Internalism $\mathrm{M}$.

There is another serious problem with the view. For some justified methods - for instance, for the basic methods governing our moral and modal thought - we don't possess any persuasive defenses. For other justified methods - for instance, for Modus Ponens and Inference to the Best Explanation - the only apparent candidate defenses are circular. For example, consider the following argument for the validity of Modus Ponens: Suppose both $\mathrm{p}$ and if $\mathrm{p}$ then $\mathrm{q}$.

So $\mathrm{p}$.

So if $\mathrm{p}$ then $\mathrm{q}$.

So q. 
So if both $\mathrm{p}$ and if $\mathrm{p}$ then $\mathrm{q}$, then $\mathrm{q}$.

So if both $p$ is true and if $p$ then $q$ is true, then $q$ is true.

Therefore, Modus Ponens is valid.

This argument relies on an instance of Modus Ponens. ${ }^{34}$

Similarly, it is natural to try to defend Inference to the Best Explanation as follows:

Inference to the Best Explanation has worked well for us in the past. The best explanation of this is that Inference to the Best Explanation is moreor-less reliable. Therefore, it is acceptable to employ this rule of inference.

This defense relies on an instance of Inference to the Best Explanation. It, too, is circular.

In response to this circularity worry, one might claim that the circularity here is not vicious. The arguments are rule-circular and not premise-circular. And it may be thought that at least some rule-circular arguments are acceptable. ${ }^{35}$

In some contexts, it is appropriate to appeal to this distinction. For instance, it may be acceptable to make use of Modus Ponens in justifying the belief that Modus Ponens is valid. The trouble is that we aren't discussing the justification of a belief. These arguments were raised as defenses of rules. It is grossly circular to defend a rule by appealing to the very rule in question. Such a defense should not be satisfying to a rational thinker.

Why not take another tack? Why not just say that we find all of these rules intuitive (or obvious or self-evident or ...)? The idea is that we have the intuition that Modus Ponens, for instance, is reliable (or otherwise has a positive epistemic status). The belief-forming methods that govern our reasoning with intuitions permit us to conclude that Modus Ponens is reliable. This provides a defense of Modus Ponens.

\footnotetext{
${ }^{34}$ Of course, we could present an argument that makes use of Reasoning by Cases or some deductive rule other than Modus Ponens. But that would just be to move the bump in the rug.

${ }^{35}$ See Boghossian (2000).
} 
This suggestion relies on endorsing several contentious theses about the existence and nature of intuitions. Even putting such worries aside, it doesn't seem to be very much of a defense to say that Modus Ponens is intuitively reliable. More importantly, we can ask the same question about our methods for reasoning with intuitions. What is our defense of these methods? On pain of vicious circularity, the defenses of the methods that govern reasoning with intuitions cannot themselves depend on reasoning with intuitions. Very generally, we cannot simultaneously defend all of our belief-forming methods, at least not in a non-trivial and non-circular way.

This point is closely connected to the final problem I'd like to raise for Defense Internalism. Namely, Defense Internalism ${ }_{M}$ leads to an infinite regress. This is because a defense of a method is justified only if the methods employed in the defense are themselves justified.

This is a familiar sort of problem. I think that it is genuinely a problem. The trouble stems from the independence requirement on defenses. Given this requirement, to possess a defense of a method requires having infinitely many other defenses. Given our finitude, this is an impossible demand to satisfy.

The reason I raise this problem here is that there is a putative way out of this problem that merits discussion. In particular, the suggestion is that the infinite regress can be blocked if Defense Internalism is restricted to rules of inference, rather than beliefforming methods more generally. This may be part of what motivates some philosophers to focus on 'inferential internalism' rather than internalism about both inferential and non-inferential reasoning. ${ }^{36}$

\footnotetext{
${ }^{36}$ For discussions of inferential internalism see Boghossian (2003), Fumerton (2006), p. 101, and Leite (2008). I should note that inferential internalist theses are typically formulated not as theses about which
} 
The trouble with this suggestion is that there is no intuitive motivation for the restriction to inference rules. The defense-based conception of responsibility motivates a very general constraint. There is no obvious reason to think, for example, that inference rules require defenses whereas perceptual methods do not.

Given all of these problems, I conclude that we ought not to adopt Defense Internalism ${ }_{\mathrm{M}}$.

Why, then, do we find the defense-based conception of justification so appealing? Why does Defense Internalism have such an intuitive pull? Again, there is plausible diagnosis that can be offered: As rational thinkers, we have several general rational obligations. For instance, we are rationally obligated to try to explain interesting phenomena and to evaluate our own patterns of thinking. ${ }^{37}$ It follows from these general obligations that we ideally ought to try to defend all of our beliefs and belief-forming methods. This is one of our rational ideals. However, this is not a constraint on justification. Although we may sometimes confuse the two, we do not need to possess a defense in order to be justified. And that is a very good thing since, as we have seen, the rational ideal is unsatisfiable. ${ }^{38}$

\subsection{Entitlement}

Before I turn to the third motivation for rule internalism, let's take stock. If what I've argued is correct, Extreme Method Internalism and Defense Internalism ${ }_{M}$ are false. So we must be justified in employing certain belief-forming methods as basic but not in virtue

rules of inference are justified but as theses about which arguments transmit justification from premises to conclusion.

${ }^{37}$ See Enoch and Schechter (2008) for discussion.

${ }^{38}$ See Christensen (2007) for discussion of unsatisfiable rational ideals. 
of having justified backing beliefs or defenses of the method. In other words, we are epistemically entitled to employ those belief-forming methods. Plausible examples of methods we are entitled to employ include Modus Ponens, Inference to the Best Explanation, and our basic perceptual methods.

This raises a question: In virtue of what are we entitled to employ certain beliefforming methods and not other? I'll have something to say about this question below. But, first, let me turn to the third and final motivation for rule internalism.

\section{The Argument from Skeptical Scenarios}

The third motivation for rule internalism is based on our intuitive reactions to skeptical scenarios. Imagine someone who is just like you, with exactly the same experiences that you are currently having and with the same beliefs about the world, but who is being radically misled by an evil demon. Alternatively, imagine that your counterpart is not being misled by an evil demon, but rather has had her brain surreptitiously removed and placed in a vat, where it is being fed experiences by a complex apparatus controlled by an evil neuroscientist. Or, alternatively, imagine that your counterpart is stuck in a Matrixlike scenario. We have strong intuitions about each of these scenarios. We find it intuitive that our counterparts are just as justified as we are in their beliefs about the world. They are just as justified as we are in the belief-forming methods they employ. Moreover, they seem justified in exactly the same way and for exactly the same reasons that we are.

These intuitive reactions support a supervenience claim. They make it plausible that justification supervenes on what is in common between us and our counterparts. This 
is another internalist thesis. ${ }^{39}$ (We'll come back to the question of how exactly to formulate the thesis.)

There is reason, however, to be wary of this line of thought. In particular, the line of thought may be the product of confusing having a justified belief with having an excusable belief. Our counterparts in the skeptical scenarios are being manipulated by an outside malevolent (or, perhaps even, benevolent) being. They are not, in some sense, 'to blame' for their beliefs. This feature of the cases may play havoc with our intuitive judgments about justification.

To address this worry, we can switch to another class of skeptical scenarios. Imagine someone who is just like you, with the very same beliefs and who - from the inside - seems to be having the same experiences, but who is not genuinely having the same experiences, because she is caught in a dream. Alternatively, imagine that your counterpart is not caught in a dream, but is having hallucinations with exactly the same character as your experiences. In each of these cases, the 'problem' (as it were) is not that some outside being is manipulating your counterpart's mental states. Rather, the problem is internal to your counterpart's mind. Scenarios such as these can be used to test whether we are confusing justification and excusability.

It will be helpful to have a single example in focus. For the sake of concreteness, let me focus on the following case.

Wishful Hallucination: Suppose that you justifiably believe that $\mathrm{p}$ on the basis of visual perception. Suppose that you have a counterpart that is exactly like you and is in exactly the same conditions as you are, with one exception. Namely, your counterpart believes that $p$ on the basis of having a visual hallucination of its being the case that $p$. The causal explanation

\footnotetext{
${ }^{39}$ This line of thought is closely related to the 'New Evil Demon' argument of Lehrer and Cohen (1983) and Cohen (1984).
} 
of the hallucination is (in part) that your counterpart subconsciously wishes it to be the case that $\mathrm{p}^{40}$

Interestingly, I find that I have equivocal intuitions about this case. On one way of thinking about the case - the 'first-personal' way - my counterpart seems to be just as justified as I am. On a different way of thinking about the case - the 'third-personal' way - my counterpart seems not to be as justified as I am.

Perhaps I have idiosyncratic reactions to the case. But suspect that this is not so. Let me try to convince you. Think about the case first-personally: Project yourself inside the head of your counterpart. Seen from the inside, the hallucination is indistinguishable from a genuine perception. Now ask yourself what you should believe given your (apparent) experiences. The answer is clear: You should believe that $\mathrm{p}$. That's what you are justified in believing.

Now consider the case third-personally - from the outside. Focus on the idea that your counterpart believes that $\mathrm{p}$ on the basis of wishful thinking. This is not an ordinary case of wishful thinking - in the case, the wish directly causes a hallucination rather than a belief. Nevertheless, it is a case of wishful thinking. It seems clear that one cannot be justified holding a belief that was formed in such a dubious way. How could this count as a good case of believing?

Not only are my reactions equivocal, but I find that I can make them switch back and forth in a fairly systematic way. If I think about the case from the inside, my counterpart seems justified. If I think about the case from the outside, my counterpart

\footnotetext{
${ }^{40}$ The wishful hallucination scenario is a case of cognitive penetration, as discussed in Siegel (2012). The case may be a useful test case for Evidentialism, as presented by Feldman and Conee (1985). The subject is, in effect, providing himself with evidence. That seems epistemically dubious.
} 
seems unjustified. I also find that I have similar reactions to other dream, hallucination, and wishful thinking cases. ${ }^{41}$

I'm not entirely sure what to make of this phenomenon. Perhaps there are two epistemic notions in play - justification and something else. If so, the difficulty is in determining which of our two reactions genuinely reflects something about justification and not a different epistemic status.

In any event, let's proceed as if the first-personal way of thinking genuinely reflects our intuitions about justification. On this way of thinking, our counterparts are just as justified as we are in their beliefs and in their employment of belief-forming methods. This supports a supervenience claim. The claim is that justification supervenes on a subset of mental states - those mental states shared between a thinker and her counterparts in the relevant skeptical scenarios. As an approximation, we can take the supervenience base to consist of the conscious mental states that make up a thinker's 'point of view'. Consider the case of a thinker with the very same point of view as you have, but with some other differences in their mental states. If you project yourself into your counterpart's head, it will be intuitive that your counterpart is just as justified as you are. $^{42}$

This line of thought motivates the following two supervenience claims:

Mental Internalism $_{B}$ : Whether a thinker is justified in believing a proposition supervenes on the mental states that make up the thinker's point of view.

\footnotetext{
${ }^{41}$ It is worth thinking about evil demon, brain in vat, and Matrix cases where it is somehow the subject's fault that she is being misled - for instance, the subject volunteered to be put in the vat and then was caused to forget this. These cases also seem to elicit equivocal intuitions.

${ }^{42}$ This supervenience basis may have to be slightly expanded. For instance, the basis may also have to include the thinker's point of view over an interval of time (as opposed to an instant). In imagining a skeptical scenario in a first-personal way, we imagine being that person for a short while. It may also have to be expanded to include some of the thinker's dispositions to form beliefs, and the like.
} 
Mental Internalism ${ }_{M}$ : Whether a thinker is justified in employing a beliefforming method supervenes on the mental states that make up the thinker's point of view.

These theses can be thought of as a generalization of Evidentialism, at least so long as a thinker's evidence is completely included in his point of view. ${ }^{43}$

Notice that Mental Internalism $\mathrm{M}_{\mathrm{M}}$ is a very different sort of internalist constraint from the two we have so far considered. There is no appeal to backing beliefs, defenses, or anything similar. Notice, too, that this constraint does not suggest a positive account of the justification of belief-forming methods. If the motivation works, it provides something like a proof of the possibility of an internalist account. It does not directly provide a positive account. ${ }^{44}$

I'd like to have a compelling objection to make against Mental Internalism $\mathrm{M}_{\mathrm{M}}$. In truth, I don't have one. But I do think there are two important reasons to resist endorsing it. First, as we've seen, our intuitive reactions to skeptical scenarios are equivocal. They do not clearly motivate Mental Internalism $\mathrm{M}_{\mathrm{M}}$. Second, as we will see in the next section, there is reason to think that no plausible account of justification satisfies the constraint.

\section{The Way Forward?}

Given the failure of the first two forms of internalism, what is needed is an account of how we can be justified in employing a belief-forming method as basic in our thought but not in virtue of having a justified backing belief or a defense of the method. In other words, we need an account of how thinkers can be epistemically entitled to employ belief-forming methods. Such an account must be appropriately normative - in particular,

\footnotetext{
${ }^{43}$ See Feldman and Conee (1985).

${ }^{44}$ I owe this observation to Christopher Hill.
} 
it must explain how employing such a method can be an epistemically responsible thing to do.

A natural suggestion at this point would be to endorse something like process reliabilism restricted to basic belief-forming methods. The suggestion would be that a thinker is entitled to employ a belief-forming method as basic in thought just in case (and by virtue of the fact that) the method is reliable. However, such a view faces many familiar problems. The most central is simply that reliability and epistemic responsibility are very different statuses. The mere fact that a method tends to get at the truth does not make it epistemically responsible to employ the method. Just consider the rule that tells us to believe a particular highly complex mathematical truth on the basis of arbitrary inputs. This rule is completely reliable - its output is a necessary truth. Yet, a thinker would not be epistemically responsible in employing this method as basic in her thought. ${ }^{45}$

I'd like to be able to say here that my own account of epistemic entitlement to belief-forming methods is the only view that has the resources to address this issue. But I cannot make that claim. There are a few accounts in the literature that make use of resources that show promise for the project of providing an explanation of epistemic entitlement to belief-forming methods. In the remainder of this paper, I'd like to briefly sketch three such accounts. I cannot compare these accounts here. I believe that my own account is the best of the three, but arguing for this claim would require delving into the details of the accounts. In what follows, I would like to stay at a very high level of generality.

\footnotetext{
${ }^{45}$ See Schechter (2019).
} 


\subsection{Proper Function}

The first account is due to Alvin Plantinga. He writes:

[A] belief has warrant for me only if (1) it has been produced in me by cognitive faculties that are working properly (functioning as they ought to, subject to no cognitive dysfunction) in a cognitive environment that is appropriate for my kinds of cognitive faculties, (2) the segment of the design plan governing the production of that belief is aimed at the production of true beliefs, and (3) there is a high statistical probability that a belief produced under those conditions will be true. ${ }^{46}$

Plantinga is here interested in the nature of warrant - that which needs to be added to true belief to get knowledge. My discussion has been focused on a different epistemic status namely, justification. Plantinga's view is also heavily reliabilist. It inherits all of the intuitive problems of process reliabilism. But I think that the governing idea can be freed from those problems.

Here is what I take to be the core insight: There is some normativity that emerges from the fact that you are 'firing on all cylinders'. More precisely, there is a kind of normative status that attaches to a cognitive faculty when it has an appropriate aim, is well-designed for its aim, and is properly functioning.

There are certainly some obscurities in this formulation. What is an appropriate aim? What is it for a faculty to have an aim? What is it to be well-designed for an aim?

But at a high-level of generality, there is something appealing about this thought.

Modifying this account for our purposes, we arrive at the following view:

A thinker is pro tanto epistemically entitled to employ a belief-forming method as basic in thought if (and by virtue of the fact that) the method is part of a cognitive mechanism that (1) has an appropriately epistemic aim - e.g., the truth; (2) is well-designed for that aim; and (3) is functioning properly. $^{47}$

\footnotetext{
${ }^{46}$ Plantinga (1993), page 46. Also see Bergmann (2006) for a related view.

${ }^{47}$ Plantinga claims that the only appropriate epistemic aim is the truth. I do not think that this is so. He also presents a conception of function that requires that the function of a cognitive mechanism depends on it
} 


\subsection{Skillful Performance}

The second account is due to Sosa. According to Sosa, a thinker has knowledge that $\mathrm{p}$ only if (1) the thinker's belief is accurate; (2) the thinker's belief is adroit - it manifests an epistemic competence; and (3) the thinker's belief is apt - it is accurate because it is adroit. $^{48}$

Sosa's thesis does not concern justification but knowledge. In particular, it concerns the sort of knowledge we can share with non-human animals (as opposed to reflective knowledge, which must satisfy further constraints). But this view makes use of resources that can again be applied to the problem that concerns us here.

Like Plantinga's view, Sosa's view is heavily reliabilist. Sosa claims that manifesting an epistemic competence is a matter of reliably getting at the truth. But we abstract his view away from this commitment. Sosa's core insight is that there is a sort of normative status that applies to things that are done skillfully whether or not they are done thoughtfully. There is a kind of normative status that attaches to a performance that is skillful or adroit. To repeat one of Sosa's motivating examples: Consider the case of a skilled archer who shoots the arrow just so - that is, in a skillful manner. There is value in

being literally designed for its function. I think this is mistaken as well. There are several other attractive conceptions of function in the literature. For example, on Wright's (1973) view, a function of a mechanism is an effect of the mechanism that explains why it is there. For instance, a function of the heart is to pump blood, since this effect is what the heart was evolutionarily selected for. See Millikan (1984) for a related view of functions. On Cummins's (1975) view, the function of a mechanism is an effect of the mechanism that enables the system of which it is a part to have some capability. For instance, on this conception, we can say that a function of a certain part of the brain is to enable one to do advanced mathematics, even if this played no role in its evolutionary history. Graham $(2012 ; 2014)$ presents an account of epistemic entitlement that makes use of Wright's conception of functions. For reasons to do with swamp people, I would be more tempted to try to make use of something like the Cummins conception. Interestingly, the resulting view would resemble Sosa's skillful performance-based view discussed immediately below.

${ }^{48}$ See Sosa (2007). 
the archer's shooting an arrow just so even if the archer has no conscious awareness of what he is doing or how he is able to do it.

Sosa's motivation for making use of the notion of a skillful performance is to answer the value problem - the problem of explaining why knowledge is more valuable than true belief. Sosa's answer is that there is value in doing something skillfully in addition to the value of doing it successfully. My suggestion here is that we might take the same basic idea and put it to a different use - that of explaining epistemic responsibility.

Modifying his view for this purpose, we arrive at the following view:

A thinker is pro tanto epistemically entitled to employ a belief-forming method as basic in thought if (and by virtue of the fact that) beliefs formed on the basis of employing the method are adroit - they skillfully manifest an epistemic competence.

\subsection{Basic Rational Obligations}

Finally, there is my own view. ${ }^{49}$ The guiding thought of this view is that there is a kind of epistemic status that attaches to a belief-forming method that is indispensable to one of the central projects of rationality. More precisely, the view has two main theses:

(i) There are certain cognitive projects that rational thinkers ought to engage in irrespective of their goals and desires. These include the projects of explaining the world around them, deliberating over what to do, planning for the future, and evaluating their own patterns of thinking.

(ii) A thinker is pro tanto epistemically entitled to employ a belief-forming method as basic in thought if (and by virtue of the fact that) employing the method is indispensable for successfully engaging in one of these rationally required projects.

\footnotetext{
${ }^{49}$ See Schechter and Enoch (2006), Enoch and Schechter (2008), and Schechter (2019). This view has affinities with some of the proposals in Wright $(2004 ; 2014)$.
} 
We have certain basic rational obligations - for instance, to explain, to deliberate, to plan, and to self-evaluate. These are the central projects of rationality. An agent who isn't engaging in these projects is not doing what she ought to do. This is where epistemic normativity bottoms out.

We have these rational obligations whether or not we are aware of them. Beliefforming methods that are sufficiently closely connected to these obligations gain a similar status - we are epistemically entitled to employ them even without a defense or backing belief.

\subsection{Mental Internalism, Again}

It is beyond the scope of this paper to defend any of these views or to adjudicate between them. What I want to emphasize here is that these three views make use of resources that just might be able to help explain how a thinker can be epistemically responsible in employing a belief-forming method as basic in her thought despite lacking a defense or backing belief of the method. Functioning properly, skillfully manifesting a competence, or successfully engaging in one of the central projects of rationality are each properties that seem potentially able to explain normative statuses such as epistemic responsibility and entitlement. These three accounts strike me as the most plausible approaches to pursue. $^{50}$

\footnotetext{
${ }^{50}$ There are other possible approaches. Very few of them, however, seem to be able to explain epistemic responsibility. The only major additional approach I can think of is to explain epistemic responsibility by appeal to presentational phenomenology. For instance, one might claim that a thinker is pro tanto epistemically entitled to employ a belief-forming method if (and by virtue of the fact that) the thinker has an intuition that presents the belief-forming method as reliable (or as having some other positive epistemic status). I have significant doubts about this approach. I suspect that we do not have mental states with presentational phenomenology for many of our basic rules and methods. More importantly, there are plenty of rules and methods that we would not be even pro tanto responsible in employing even were we to have intuitions that presented them as reliable - for instance, consider the rule that permits one to infer some
} 
Let me leave off with one final point: None of these accounts is straightforwardly compatible with Mental Internalism. The difficulty for the proper function-based view is that it is plausibly a contingent matter what the aim or function of a cognitive mechanism is. The function of a cognitive mechanism is bound up with the mechanism's causal history, links with other mechanisms, and so on. Similarly, it is plausibly a contingent matter what counts as a skillful performance. A skillful archer on the Earth would not count as skillful on Mars. A skillful perceiver in our present environment would not count as skillful in other environments.

It is also plausibly a contingent matter what is indispensable for successfully engaging in a rationally required project, at least in the relevant sense of 'indispensable'. Consider, for example, the project of explaining the world around us. No method is absolutely indispensable for this project - the world may be such that by employing any particular method, we come to acquire all true explanations in a flash of mystic insight. So for the account to work, there must be some other notion of indispensability at issue. Plausibly, the relevant notion of indispensability is one restricted to some relevant set of possible worlds - say, the 'pragmatically relevant' possible worlds. But it is a contingent matter what is pragmatically possible. ${ }^{51}$

All of this certainly requires further discussion. But the main point is that each of these three views apparently makes use of facts about the world that are contingent and which do not supervene on the relevant thinker's point of view. ${ }^{52}$

complicated mathematical theorem from the relevant basic axioms in a single step. See Schechter (2019) for discussion.

${ }_{52}^{51}$ See Enoch and Schechter (2008) for detailed discussion.

${ }^{52}$ Why not solve this problem by rigidifying the accounts to the actual world (or to some set of 'normal worlds')? One problem is that it is not at all clear why the epistemic status of a thinker's belief-forming method in some counterfactual scenario should depend on what the actual world is like (or how we actually take it to be). A second problem is that the suggestion respects the letter of Mental Internalism while giving 
Why is it, then, that we are misled by the skeptical scenarios into thinking that Mental Internalism is true? I'm not at all certain of the answer, but I do have a hypothesis. It is plausible that the inputs to justified rules and methods must be the sorts of mental states that can be within the relevant thinker's point of view. ${ }^{53}$ So it is plausible that, fixing the rules and methods that a thinker is justified in employing, the beliefs that the thinker is justified in having supervene on the thinker's internal mental states. In imagining the skeptical scenarios we are tacitly (and mistakenly) imagining that our counterparts are justified in employing the very same rules and methods that we are. This explains our mistake.

\section{$7 \quad$ Conclusion}

The main morals of this paper are as follows: Extreme Method Internalism is unacceptable. Defense Internalism $\mathrm{M}_{\mathrm{M}}$ is also unacceptable. This raises the question of how we can be epistemically responsible in employing certain belief-forming methods as basic despite lacking backing beliefs or defenses. There are resources that we may be able to deploy to answer this question. However, the resulting views seem incompatible with Mental Internalism $\mathrm{M}_{\mathrm{M}}$, despite its initial plausibility. Thus, perhaps surprisingly, there is reason for us to be externalists about epistemic responsibility.

Here, then, is what I suggest. We should try to develop a view of justification for basic belief-forming methods that doesn't require backing beliefs or defenses. If such a view turns out to be compatible with Mental Internalism, great! Otherwise, we need to

up on its spirit. The thought behind Mental Internalism isn't merely that whether a thinker is justified supervenes on the thinker's mental states, but that it depends only on the mental states. The rigidification trick gives up on this dependence. Also see Lewis (1989) for an eloquent explanation of why rigidifying is intuitively problematic.

${ }^{53}$ See Wedgwood (2002). 
find a way to explain away some of our intuitive reactions to skeptical scenarios. That's the hard work in this area of epistemology that we need to do. ${ }^{54}$

\section{References}

Austin, J. (1956). A plea for excuses. Proceedings of the Aristotelian Society, 57, 1-30

Bergmann, M. (2006). Justification without awareness: A defense of epistemic externalism. (Oxford: Oxford University Press)

Boghossian, P. (1989). The rule-following considerations. Mind, 98, 507-549

Boghossian, P. (2000). Knowledge of logic. (In P. Boghossian \& C. Peacocke (Eds.) New essays on the a priori (pp. 229-254). Oxford: Oxford University Press.)

Boghossian, P. (2005). Rules, meaning, intention. Philosophical Studies, 124, 185-197

Boghossian, P. (2008). Epistemic rules. (In his Content and justification: Philosophical papers (pp. 109-134). Oxford: Oxford University Press.)

BonJour, L. (1980). Externalist theories of empirical knowledge. Midwest Studies in Philosophy, 5, 53-73

BonJour, L. (1985). The structure of empirical knowledge. (Cambridge, Mass.: Harvard University Press)

Burge, T. (1993). Content preservation. The Philosophical Review, 102, 457-488

Carroll, L. (1895). What the tortoise said to Achilles. Mind, 4, 278-280

Christensen, D. (2007). Does Murphy's law apply in epistemology? Self-doubt and rational ideals. Oxford Studies in Epistemology, 2, 3-31

Cohen, S. (1984). Justification and truth. Philosophical Studies, 46, 279-96

Cummins, R. (1975). Functional analysis. Journal of Philosophy, 72, 741-745

Dretske, F. (2000). Entitlement: Epistemic rights without epistemic duties? Philosophy and Phenomenological Research, 60, 591-606

Enoch, D. and Schechter, J. (2008). How are basic belief-forming methods justified? Philosophy and Phenomenological Research, 76, 547-579

Feigl, H. (1952). Validation and vindication: An analysis of the nature and limits of ethical argument. (In W. Sellars and J. Hospers (Eds.) Readings in ethical theory (pp. 667-680). New York: Appleton-Centur-Crofts.)

Feldman, R. \& Conee, E. (1985). Evidentialism. Philosophical Studies, 48, 15-34

Fine, K. (2001). The question of realism. Philosophers' Imprint, 1, 1-30

Fine, K. (2012). Guide to ground. (In F. Correia and B. Schnieder (Eds.) Metaphysical grounding: Understanding the structure of reality (pp. 37-80). Cambridge: Cambridge University Press.)

Fumerton, R. (2006). Epistemology. (Malden, Mass.: Wiley-Blackwell)

Goldman, A. (1999). Internalism exposed. Journal of Philosophy, 96, 271-93

\footnotetext{
${ }^{54}$ An earlier version of this paper was presented at a workshop on Inferential Internalism at the University of Fribourg in 2008. I would like to thank Philipp Blum, Julien Dutant, Pascal Engel, Adam Leite, Jim Pryor, and Andri Toendury for questions and comments at the workshop. I'd like to thank Paul Boghossian, David Enoch, and Christopher Hill for discussion at various stages of this project. I'd also like to thank Peter J. Graham and an anonymous referee for helpful comments.
} 
Graham, P. (2012). Epistemic entitlement. Noûs, 46, 448-482.

Graham, P. (2014). Functions, warrant, history. (In A. Fairweather and O. Flanagan (Eds.) Naturalizing epistemic virtue (pp. 15-35). Cambridge: Cambridge University Press.)

Hill, C. (2006). Modality, modal epistemology, and the metaphysics of consciousness. (In S. Nichols (Ed.). The architecture of the imagination (pp. 205-236). Oxford: Oxford University Press.)

Jenkins, C. (2011). Is metaphysical dependence irreflexive? The Monist, 94, 267-76

Kripke, S. (1982). Wittgenstein on rules and private language. (Cambridge, Mass.: Harvard University Press)

Lehrer, K. (2000). Theory of knowledge, second ed. (Boulder: Westview)

Lehrer, K. and Cohen, S. (1983). Justification, truth, and coherence. Synthese, 55, 191207

Leite, A. (2008). Believing one's reasons are good. Synthese, 161, 419-441

Lewis, D. (1989). Dispositional theories of value. Proceedings of the Aristotelian Society, Supplementary Volume, 63, 113-137

Littlejohn, C. (forthcoming). A plea for epistemic excuses. (In F. Dorsch and J. Dutant (Eds.) The new evil demon problem. Oxford: Oxford University Press.)

Millikan, R. (1984). Language, thought, and other biological categories. (Cambridge, Mass.: The MIT Press)

Plantinga, A. (1993). Warrant and proper function. (Oxford: Oxford University Press)

Rosen, G. (2010). Metaphysical dependence: Grounding and reduction (In B. Hale and A. Hoffmann (Eds.) Modality: Metaphysics, logic, and epistemology (pp. 109-136). Oxford University Press.)

Schaffer, J. (2009). On what grounds what. (In D. Chalmers, D. Manley, \& R. Wasserman (Eds.) Metametaphysics (pp. 347-383). Oxford: Oxford University Press.)

Schaffer, J. (2012). Grounding, transitivity, and contrastivity. (In F. Correia and B. Schneider (Eds.) Metaphysical grounding: Understanding the structure of reality (pp. 122-138). Cambridge: Cambridge University Press.)

Schechter, J. (2010). The reliability challenge and the epistemology of logic. Philosophical Perspectives, 24, Epistemology, 437-464

Schechter, J. (2019). Small steps and great leaps in thought: The epistemology of basic deductive rules. (In M. Balcerak Jackson \& B. Balcerak Jackson (Eds.) Reasoning: New Essays on Theoretical and Practical Thinking (pp. 152-177). Oxford University Press.)

Siegel, S. (2012). Cognitive penetration and perceptual justification. Noûs, 46, 201-222

Sosa, E. (2007). A virtue epistemology: Apt belief and reflective knowledge. (Oxford: Oxford University Press)

Strawson, P. (1962). Freedom and resentment. Proceedings of the British Academy, 48, $1-25$

Wedgwood, R. (2002). Internalism explained. Philosophy and Phenomenological Research, 65, 349-369

Williamson, T. (2000). Knowledge and its limits. (Oxford: Oxford University Press) Williamson, T. (2007). The philosophy of philosophy. (Oxford: Oxford University Press) 
Williamson, T. (forthcoming). Justification, excuses, and sceptical scenarios. (In F. Dorsch and J. Dutant (Eds.) The new evil demon problem. Oxford: Oxford University Press.)

Wright, C. (2004). Warrant for nothing (and foundations for free)? Proceedings of the Aristotelian Society, Supplementary Volume 78, 167-212

Wright, C. (2014). On epistemic entitlement (II): Welfare state epistemology. (In D.

Dodd and E. Zardini (Eds.) Scepticism and perceptual justification (pp. 213-247).

Oxford: Oxford University Press)

Wright, L. (1973). Functions. The Philosophical Review, 82, 139-168. 